The Arbutus Review • 2018• Vol. 9, No. 1 • https://doi.org/10.18357/tar91201818381

\title{
Being as Value: The Phenomenology of Value and the Ontology of Self-Realization in Charles Taylor's Sources of the Self
}

\author{
Andrada-Elena Holmgren * \\ University of Victoria \\ elena.holmgren@gmail.com
}

\begin{abstract}
This article explores one way of putting selves and values back into the world. I analyze Charles Taylor's, Iris Murdoch's, and Donald Walhout's arguments showing that to be a self is to relate to being as a value. I show that the intentional relation of world-directedness that is central to self discloses being first as a value. I argue that our best account of what it is to be a self commits us to the objectivity of values.

I then explore Taylor's arguments that, by denying a place for objective values in nature, the standard naturalist ontology leaves a gap between nature and self. I argue that this gap arises because current naturalism cannot account for the place of the intentional relation in the world, the latter of which is our first guide to value. It thereby leaves a gap between third- and first-personal perspectives that obscures the nature of values as properties of relational situations. I explore Michiel Meijer's objection that Taylor leaves an unresolved gap between ontology and phenomenology in his defense of value realism. I draw on the little-known work of Donald Walhout to show how this gap can be filled by analyzing value in terms of function.

Keywords: Metaphysics of self; metaphysics of value; naturalism; phenomenology; experience
\end{abstract}

The existential attitude is one of involvement in contrast to a merely theoretical or detached attitude. "Existential" in this sense can be defined as participating in a situation, especially a cognitive situation, with the whole of one's existence. ... There are realms of reality or - more exactly - of abstraction from reality in which the most complete detachment is the adequate cognitive approach. Everything which can be expressed in terms of quantitative measurement has this character. But it is most inadequate to apply the same approach to reality in its infinite concreteness. A self which has become a matter of calculation and management has ceased to be a self. It has become a thing. You must participate in a self in order to know what it is. But by participating you change it. In all existential knowledge both subject and object are transformed by the very act of knowing. Existential knowledge is based on an encounter in which a new meaning is created and recognized. (Paul Tillich, 1952, pp. 123-124)

1 his article argues that the metaphysics of self depends on the metaphysics of value. I argue that to be a self is to relate to being as a value. In everyday life, we encounter ourselves in value situations that are never entirely our own making. For instance, consider the experience of seeing a beloved corner of nature. The pattern of what we see is born of the interplay between

* Many thanks to my supervisor Dr. David Scott for his support, feedback, reading recommendations, as well as for teaching me most of the background on Aristotle - in particular his notion of function - upon which I draw here. Thanks also to JCURA for funding the research out of which this essay grew, and for the peer reviewers and editors of The Arbutus Review for their insightful suggestions for revision. 
The Arbutus Review • 2018• Vol. 9, No. 1 • https://doi.org/10.18357/tar91201818381

what we bring to the scene (our capacities and predispositions) and the form of the landmarks themselves. If we bring a friend, we are struck by the fact that each one of us sees a different landscape in the same place. And yet, we also know the place as a site of possible convergence between the various gazes of the subjects that enter into it: I can show you the mossy heap. As this commonplace example of aesthetic perception illustrates, we are used to the fact that our being there with things makes a pattern from which we can isolate our contribution and that of things only through an artificial, after-the-fact analysis. Aesthetic perception is chosen here because it is perhaps the most common and well-known experience of value. In this case, aesthetic experience discovers the intrinsic value of the moss. By intrinsic value, I mean the value that a thing has "in itself," by virtue of the way that it is. The moss is known to have intrinsic value because it acts as the co-creator of the value situation (the emerald hue) that I see. It would be a different green were the moss any different from what it is. Such experiences reveal how our being there with things creates a value that is not reducible to our subjective contribution. They also reveal how our being a self is intimately bound up with this cooperative co-creation of values.

The problem, as Charles Taylor points out in his seminal work Sources of the Self, is that the philosophical picture of nature that interprets modern science today leaves no room for this experience that is so central to selfhood. On this naturalistic view, there is no element of discovery in value experience. Rather, values are features of mental states that we project onto a valueless world. In this perspective, we can reduce all talk of values to descriptive talk about psychological facts (namely, the contingent beliefs and desires of the individual). If this view is correct, then, in the example above, the moss itself has nothing to do with the value that it comes to have for us, except as a material to be shaped as we please according to our subjective interests. This is a problem because, as Taylor argues, our best account of self implicitly commits us to the objectivity of values. By objectivity of values, I mean those values, such as beauty or truth, that lie outside the individual and that do not depend on that individual's mental states alone. Taylor argues that selves are crucially grounded in the world through their orientation to those regions of the real that they register as intrinsic goods. Thus, value distinctions are an ineliminable part of our starting point as thinkers. As a result, objective values must be given a central place in any ontology. Hence, as far as ontological status goes, Taylor argues that selves and values must either stand or fall together.

Taylor shows that if the standard naturalist ontology of our day is correct, a conflict arises between the explanation of nature and the explanation of self. One must be eliminated in favour of the other. We are left with a dilemma. If we choose in favour of nature by eliminating value experience, we're left with an incoherent ontology of self that implicitly presupposes the objective values that it purports to explain away. And if instead we choose in favour of self, we lose all continuity between nature and experience, thereby leaving an insuperable divide between practical, evaluative reason, on the one hand, and theoretical, scientific reason, on the other. Moreover, since value is a co-creation between nature and self, we lose sight of the relational situation in which value emerges, too. This unresolved conflict makes finding a unified explanation of our place in the natural world unattainable in principle. Instead, all we can have is a fractured paradigm composed of two autonomous spheres: the world of meaningful experience and the alien world of fact.

I argue that Taylor rightly diagnoses the problem with current naturalist ontologies of both value and self. However, he fails to offer an alternative metaphysical account that solves the issue of grounding the objectivity of values, and therefore of putting selves back into our divided picture of being. Ultimately, there remains a gap between Taylor's phenomenological arguments, which reveal the inconsistency between our best account of self and the ontology of natural science and his ontological conclusions that naturalist ontology requires substantive revision. It remains unclear in just what that revision consists.

Donald Walhout's The Good and the Realm of Values provides a possible way of bridging the gap 
The Arbutus Review • 2018• Vol. 9, No. 1 • https://doi.org/10.18357/tar91201818381

that remains between phenomenology and ontology in Taylor's arguments. I show how Walhout's concept of function bridges the gap between the first- and third-personal perspectives, between the normative and the descriptive, between value and being. As such, it can offer a positive alternative to naturalism that secures the objectivity of value that our best account of self presupposes. I conclude that we need to revise our current exclusively third-personal naturalist ontology in favour of a first-personal naturalism based on a revised Aristotelian bridge concept of function. This first-personal naturalism allows us to define objective value as complete being, or as fully realized functioning.

I argue that the divide between the normative and the theoretical dimensions of explanation can be bridged only if we recognize both the logical and the ontological priority of the first-person stance in our worldview. In particular, this divide can be bridged if we recognize, like Iris Murdoch, that the idea of value is a regulative principle of all reasoning, rather than being some epiphenomenal side-issue, as naturalistic ontology makes it out to be. I strive to show that our first knowing encounter with the world is through our intentional relation to reality experienced as a value for us. If this analysis is right, then there is no complete metaphysical explanation without a normative component. This evaluative dimension makes merely theoretical knowledge existentially transformative in Tillich's sense. An essential part of what it is to really know something is to grasp its value for the self. This grasp of value grounds knowledge in the "infinite concreteness" of individual encounter. Grasping the value dimension of situations is what turns knowledge into understanding, as opposed to just a formal exercise.

In all explanations, we must begin where we are: that is, in the first-person stance, where being is first known as a value. And, once explanation is complete, we must connect our theories to where we started from and still remain, despite all our theorizing.

\section{Overview}

In the first section, Taylor's and Murdoch's phenomenologies of value are outlined. Taylor introduces a distinction between procedural and substantive reasoning. The former is the model of practical reason enshrined in contemporary naturalist ethics, which locates value exclusively in mental states or in properties of acts. Instead, Taylor follows Murdoch by arguing in favour of a view of moral reasoning as substantive, which, unlike procedural reason, is contentful. Substantive reason goes beyond an analysis of formal action procedures in its striving to identify those goods that are the proper objects of love and that empower the self, qua creative agency, in its pursuit of realization. I show that if Taylor's view of practical reasoning as substantive is correct, then morality, by concerning itself with the proper relation between self and the rest of reality, implicates us in the metaphysics of self and value.

The second section offers an overview of Taylor's arguments for the conceptual priority of the first-person stance. In particular, I examine the dual role his "Best Account" (BA) principle plays in both his phenomenological analysis of the structure of value judgments and in his ontological argument for the insufficiency of naturalism as a theory of self and of value. I then explore how the BA principle, by revealing the superiority of a model of substantive reason over the procedural model of naturalist ethics, implicitly commits Taylor to ontologically-grounded value distinctions.

The third section highlights the gap that remains in Taylor's account between phenomenological and ontological arguments for the objectivity of values. In particular, I support Michiel Meijer's claim that Taylor's transcendental arguments may tell us what the best account of experience might be, but they are not by themselves guides to the objective features of the world. Therefore, they cannot be used to determine whether values are ineliminable in a metaphysics of self. If Meijer is correct, Taylor cannot legitimately use his BA principle as a criterion by which to evaluate ontologies. 
The Arbutus Review • 2018• Vol. 9, No. 1 • https://doi.org/10.18357/tar91201818381

I ultimately agree with Meijer that Taylor needs something more than just transcendental arguments if he is to escape both the closed circle of post-Kantian subjectivism and the incoherence of current naturalist accounts.

The fourth section proposes what that "something more" might look like. I show how Donald Walhout's phenomenology of moral judgment complements Taylor's own but does so while making its ontological commitments more fully explicit. Ultimately, Walhout's discussion of value as the realization of a being's characteristic function provides us with a plausible metaphysics of Taylor's substantive reason. It also provides us with the basis for conceiving what a first-person naturalism that satisfies Taylor's Best Account principle might look like.

\section{What is Value, Anyway?: Taylor's and Murdoch's Phenomenology of Value Judgment}

Since values are known first through experience, "a phenomenological account of identity" is the proper method for the study of value (Taylor, 1989, p. 32). Taylor argues that contemporary naturalist moral philosophy operates with a flawed procedural model of practical reason that sees moral reasoning as a set of formal action procedures. And yet, surely, as Taylor points out, the procedural question of "what it is right to do" logically depends on the answer to the substantive question of "what it is good to be" (1989, p. 79). This is because determining the content of obligation presupposes a prior answer to the question concerning what the good life considered as a whole might be, since it is through reference to such a view that we can evaluate the relative moral priority of our various obligations. As such, it is the latter domain of substantive reasoning that forms the more basic, as well as the more comprehensive, category of moral deliberation.

What's missing in naturalist understandings of practical reason, then, is any notion of "what it may be good (or even obligatory) to be or love" (Taylor, 1989, p. 79). In order to recover a notion of moral value that makes sense of our experience, we need: i) a vision of the good life, which displays how the good person is related to reality, ii) a notion of intrinsically valuable being ("what is valuable in itself, or what we should admire or love"), and iii) a determination of the proper objects we cannot but make reference to in our striving to realization, since striving doesn't occur in an ontological vacuum, but is motivated by a relation to something beyond the self (i.e., the self's "objects of love and allegiance") (Taylor, 1989, p. 84, 79).

The issue is that the procedural view shows a bias towards identifying value with action considered in just such an ontological vacuum. "Good" and "bad" are on this view supposed to be properties that attach to actions considered without reference to being, either the being of the actor, or that of the acted-upon. Instead, Taylor argues that moral judgments presuppose ontological determinations. He points out that the analysis of action as the exclusive place of value presupposes the larger background understandings of being that form the enabling context of action, which Taylor calls our "background pictures." A background picture is "the moral ontology which articulates [our] intuitions" (Taylor, 1989, p. 8). In order to act, we implicitly draw on a moral ontology that situates us in being by presenting us with a systematic view of the world that places us in it as moral agents. This ontology specifies the nature of the relation that we adopt towards being in any given action (Taylor, 1989, pp. 5, 9). Moreover, a background picture is an "inescapable framework" or horizon within which our lives can be seen as a meaningful whole (Taylor, 1989, p. 17). Taylor describes "acting within a framework as functioning with a 'sense' of a qualitative distinction" (p. 21). Defining what it is to act in terms of functioning with a background understanding of qualitative distinctions, where qualitative distinctions are taken to be "defining orientations," suggests that a value orientation is constitutive of agency (Taylor, 1989, p. 41). A framework of qualitative distinctions then is a condition for the possibility of agency. A framework can thus be described as a first-personal view of 
existence from the standpoint of value. To be an agent, on this view, is to navigate being through an orientation to value.

The crucial point is that all moral reactions are "implicit acknowledgments of claims concerning their objects" (Taylor, 1989, p. 7). Moral judgments, as well as value judgments generally, involve an orientation to mind-independent features of the object, the latter of which constrain the range of our possible evaluations, as we saw in the example of aesthetic perception. Taylor calls the capacity for qualitative distinctions that lies at the basis of these judgments "strong evaluation." Strong evaluations are "discriminations of right or wrong, better or worse, higher or lower, which are not rendered valid by our own desires, inclinations, or choices, but rather stand independent of these and offer standards by which they can be judged" (Taylor, 1989, p. 4). Because we experience these goods as being true independently of our mental states, they act as independent, objective reference points that allow us to evaluate the worth of our subjective states. We judge the goods disclosed by strong evaluation as "incomparable" in the sense that they do not admit of degree: they are "not just more desirable, in the same sense though to a greater degree, than some of these ordinary goods are" (Taylor, 1989, p. 20). Instead, they are implicitly accorded "special status" in our reasoning around which all else is organized (Taylor, 1989, p. 20). Value judgments are not just some epiphenomenal side-issue, then: They are at the heart of reasoning in its practical modality.

The immediate object of practical reason is what Taylor calls a "constitutive good":

The constitutive good does more than just define the content of the moral theory. Love of it is what empowers us to be good. And hence also loving it is part of what it is to be a good human being. This is now part of the content of the moral theory as well, which includes injunctions not only to act in certain ways and to exhibit certain moral qualities but also to love what is good (1989, p. 93).

A value, so understood, is the shape of the real for us, as an object of love and striving. Now we are in a position to understand the meaning of Taylor's poignant phrase, "sources of the self." Constitutive goods are the sources of the self insofar as they provide our experience with content and directionality. It is because of this that they can, I would argue, be understood as the ultimate objects of intentionality. We first pick out the real as a value for us. If Taylor is right, value is the real seen from the first-person stance of the subject.

Moreover, strong evaluation is a condition for the possibility of self-knowledge. Taylor makes the radical claim that strong evaluation is not only a core part of moral reason, but also the instrument that makes possible the twin processes of self-knowledge and self-construction:

To know who I am is a species of knowing where I stand. My identity is defined by the commitments and identifications which provide the frame or horizon within which I can try to determine from case to case what is good, or valuable, or what ought to be done, or what I endorse or oppose. In other words, it is the horizon within which I am capable of taking a stand. (Taylor, 1989, p. 27)

Thus, to know who I am is to identify my characteristic orientation to those regions of being that I register as constitutive goods. This relation to the good just is the individuating principle of selves, in Taylor's view. The spatial metaphors in such passages imply the situatedness and involvement of selves with being, even in their most intimate acts of self-knowing. The fact that identity is "defined" only within a "horizon" within which qualitative distinctions of what ought to be endorsed or opposed suggests that there is an inextricable link between the process of identity formation and the process of moral judgment. "Selfhood and the good, or in another way selfhood and morality, turn out to be inextricably intertwined" (Taylor, 1989, p. 3). To be a self is to affirm a position in 
what Taylor calls "moral space" (p. 25). Thus, because self-knowledge is intrinsically a process of orientation to being, it is impossible without qualitative distinctions of being.

The process of self-knowledge involves the articulation of a narrative structure that traces my trajectory towards the strongly valued good that explains the direction I see my life taking. A narrative answers the question of who I am by making explicit my relation to the good at different points in my life (Taylor, 1989, p. 47). I find out where I am in my life by plotting my movement either towards, or away from, the good that I recognize as binding on me. Suppose that the goal that would give my experience meaning would be to learn as much as I can about the subject that I am most passionate about. Suppose also that doing this requires that I go against the grain of my lazy nature, tempted, as it is, to cut corners whenever possible. Further, suppose that my cutting corners, while keeping me from genuine understanding, would nonetheless produce work whose deficits are not noticed by others and that therefore would not be penalized, not even in the long run. One could say that cutting corners pays in such cases, as far as any merely external measures (pragmatic, social) can say. Nevertheless, there is still something available to me in such cases that directs me in evaluating my situation when all external measures, of the kind that naturalists rely on, fail. In other words, I still know that I am somehow cheating myself by cutting corners, even when it makes no externally observable difference to do so. I know this because understanding is for me a constitutive good that is not merely defined according to contingent, social, pragmatic, or even (my own) subjective measures. Rather, the content of the goal, "genuine understanding," is fixed for me in a way that other such extrinsic measures are not. Hence, to know who and where I am in my life at any given moment, I implicitly position myself in relation to the goods, such as understanding, that I recognize as constraints on my possible range of actions. I progressively begin to see my life as a whole, structured around the goal of understanding. I determine how I am doing by measuring the distance between where I am (lacking in understanding) and where I ought to be (an epistemically complete agent).

Taylor's point is that, without reference to such goods, we cannot make sense of the narrative shape and direction that our lives actually take. We understand who and where we are in our lives in relation to the absolute reference point of a constitutive good (Taylor, 1989, p. 47). Ultimately, life stories map out positions in moral space. Thus, explaining how life stories are possible ontologically commits us to the existence of the moral space that alone grounds them. An adequate moral ontology must make this implicit reference explicit.

Taylor's analysis here of the normative structure of reason displays its indebtedness both to Iris Murdoch and to Kant. In The Sovereignty of Good (1986), Murdoch showed that moral concepts are unlike empirical concepts in that they are synthetic a prior $1^{1}$ truths that are best analyzed as ideal limits against which we measure our progress and activity in experience (p. 28). Unlike empirical concepts, they cannot be accounted for in terms of a genetic analysis that reveals their psychological, causal history. On her view, a value term can best be understood as "an ideal end-point, as a concept infinitely to be learned, as an individual object of love" (Murdoch, 1986, p. 29). Murdoch (1986) ultimately argues for a Kantian view of reason as intrinsically normative: "Reason itself is (for Kant) an ideal limit: indeed his term 'Idea of Reason' expresses precisely that endless aspiration to perfection which is characteristic of moral activity" (p. 31). In her view, "the magnetic pull of the idea of perfection," or of the intrinsically good, is a central regulative standard of practical

\footnotetext{
${ }^{1}$ In Kant's terminology in the Critique of Pure Reason, synthetic a priori judgments are synthetic by virtue of the fact that their predicate is not logically contained in the subject, and are a priori because they are known independently of experience. Murdoch claims that value judgments are a class of synthetic a priori judgments that have a regulative use by providing stable coordinates to which we refer as we actively organize our experience into a unified whole. The fact that value judgments are both synthetic a priori and regulative implies that their meaning is not dependent on any empirical facts that we could come upon. No empirical facts could fix the content of the proposition "understanding is a supreme value of human life."
} 
The Arbutus Review • 2018• Vol. 9, No. 1 • https://doi.org/10.18357/tar91201818381

reason, in the sense that it is only by this idea that we can conceive of our experience as a coherent whole (p. 43). As we saw above in the example concerning the pursuit of understanding, thinking according to value concepts helps us achieve a unity that is otherwise missing in our lives (p. 94). Altogether, Murdoch (1986) rightly points out that this analysis of value concepts as ideal limits "bring $[\mathrm{s}]$ the idea of value, which has been driven by science and logic into a corner, back to cover the whole field of knowledge" (pp. 29-30).

Thus it is that "moral concepts do not move about within a hard world set up by science and logic. They set up, for different purposes, a different world" (Murdoch, 1986, p. 28). The world they set up is the world of experience, in which reality is first known as a value for the self. "Reality' and 'individual' present themselves to us in moral contexts as ideal end-points or Ideas of Reason. This surely is the place where the concept of Good lives. 'Good': 'Real': 'Love.' These words are closely connected," writes Murdoch (p. 42). In this view, goodness is connected with knowledge, and moral judgments are of reality. They are contentful, rather than formal. However, in the moral sphere, "knowledge," "truth," and "reality" acquire a different sense than they do in the scientific sphere. For Murdoch (1986), "the idea of 'objective reality' for instance, undergoes important modifications when it is to be understood, not in relation to 'the world described by science', but in relation to the progressing life of a person" (p. 26). The upshot for Murdoch, as for Taylor, is that moral knowledge is finding in the real "the proper object[s] of love" (1986, p. 68) and striving. If Murdoch is right, the taking up of a moral perspective is an inextricable part of what it means to really understand the world.

If Taylor's and Murdoch's analyses of the phenomenology of value judgment are correct, the model of procedural reason that naturalist ethics operates with provides an underdetermined account of practical reasoning that fails to explain its implicit reliance on a background ontology of value. If acting implies functioning with an implicit ontology of value, then any ethics that takes a view of reasoning that denies this fact cannot in principle get us at the whole truth about either agents (as acting selves) or values (as the intentional correlates of acts).

Ultimately, Taylor's model of substantive reason, together with his rethinking of the concept of moral value as a constitutive good that is contentful and empowering rather than merely formal and procedural, suggests that we cannot separate ethics from metaphysics. This is because ethics asks questions about the true nature of self, about the conditions of self-realization, and about the kind of relation to the real that sustains self-realization and the good life.

The problem, as we shall see in Part 2, is that there is no place for either substantive reason or for its qualitative distinctions in contemporary naturalist ontology. Our naturalist paradigm accounts for reality as an object of theoretical study, but lacks the conceptual resources for displaying such a reality as a fit "object of love" and striving. Failing to account for the real as an adequate bearer of the qualitative distinctions without which we cannot make sense of our lives means that there is a split between the theoretical explanation of natural science, on the one hand, and the kind of knowing by which we shape our lives into a coherent whole, on the other. A seemingly unbridgeable gap between these two rational modalities of explaining and evaluating remains, and we are left with an ontology without any place for the self as we live it.

Using Taylor's analysis, we can reformulate the challenge for value realism today as being one of explaining the place of substantive reason in the world. Moreover, we must somehow make sense of constitutive goods as being both objectively-binding constraints on experience, and mind-independent. The answer is found in a first-personal naturalism. 
The Arbutus Review • 2018• Vol. 9, No. 1 • https://doi.org/10.18357/tar91201818381

\section{Putting the First-Person First: Strong Evaluation and the Arguments Against Naturalism}

As we saw above, identifying moral value with the good life, together with the various kinds of objectively-grounded qualitative determinations of being that that identification entails, means that neither value theory, nor any account of the self as moral subject, can do without metaphysics. Moreover, Murdoch's and Taylor's phenomenological analyses have revealed that value terms are "inescapable structural requirements of human agency" (Taylor, 1989, p. 52). Thus, we cannot think of value without self, or of self without value. What this part shows is that we must begin to look for the ontological grounding of value in the ontology of the first-person, subjective perspective. I do this by looking at Taylor's arguments that phenomenology ought to be seen as a constraint on ontology.

As we saw above, all moral judgments are implicit affirmations of a background ontology. This being so, the challenge for us is to make our implicit moral ontologies explicit, and to then see which ones offer the best explanation of experience. Taylor introduces what he calls the "Best Account" (BA) principle as a criterion for evaluating the phenomenological consistency of various ontologies of self and value. The principle states that phenomenological adequacy must be a central criterion for evaluating the truth of ontologies. This to say that any ontology must be able to place us, as we recognize ourselves in our experience, on the map of "what there is" if it is to be able to guide our life practice. Hence, Taylor (1989) argues

the aim of this account is to examine how we actually make sense of our lives, and to draw the limits of the conceivable from our knowledge of what we actually do when we do so. But what description of human possibilities, drawn from some questionable epistemological theories, ought to trump what we can descry from within our practice itself as the limits of our possible ways of making sense of our lives? After all, the ultimate basis for accepting any of these theories is precisely that they make better sense of us than do their rivals. If any view takes us right across the boundary and defines as normal or possible a human life which we would find incomprehensible and pathological, it can't be right. (p. 32)

According to the BA principle, those concepts without which we cannot make sense of our lives should set our priorities in determining the order of ontological explanation. Thus, ontology does not only have the theoretical function of grounding science. It must also make sense of the form of experience as we cannot help but live it. In this sense, Taylor denies that we can ever take experience just as an object for theorizing. Rather, it is a continuum of interchanges with our world, one in which we are always inextricably involved. Taylor here draws on a distinction between theoretical and existential knowing familiar to existentialists such as Tillich. The former characterizes reality (including that of self and value) as an object that we can view from a perspective built on abstraction. The latter discloses reality only insofar the self is "involved" with it, or stands in relation to it (Tillich, 1952, pp. 123-124). The BA principle merely states that there must be no conflict between the two in a complete ontology. Where we must choose between the one and the other, we must never choose in favour of theoretical over existential knowledge of the self.

Ultimately, the BA principle establishes "that the horizons in which we live must include strong qualitative discriminations" (Taylor, 1989, p. 32) and that naturalist ontologies of self and value are false due to their failure to account for this fact. Taylor thus uses this phenomenological principle in exposing the gap in naturalist ontology where self and value should be. In particular, the principle forms the basis of three main arguments against naturalist ontology. First, he uses it to show that the naturalist assumption of a value-neutral stance fails to account for the moral phenomenology 
of a functioning human subject and is, as such, conceptually incoherent. Second, naturalism, like procedural theories of practical reason, implicitly presupposes the strong evaluation view that it explicitly refutes. Finally, naturalism leaves an unbridgeable gap between theoretical and existential knowing that fails to account for practical reason as an ontologically-situated activity.

First, Taylor argues that naturalism, in seeking to expunge value from ontology, creates a conceptually incoherent stance. This is because the naturalist is implicitly committed to the conceptually incoherent fiction of a "superman of disengaged objectification" (Taylor, 1989, p. 27). That is, if the naturalist value-free ontology is right, it must be possible to conceive of "an agent free from all frameworks" or what Taylor calls a "disengaged, punctual" subject who is defined merely by self-consciousness and by its contingent collection of mental states (Taylor, 1989, p. 27). Recall that Taylor has shown that the primary way that the real is given to the self is as a value with which the self is involved in the making of its life story. This shows that frameworks are conditions for the possibility of subjectivity, and that, as such, they form an integral part of the structure of the first-person stance. As Taylor (1989) puts it, "living within such strongly qualified horizons is constitutive of human agency, [such] that stepping outside these limits [as naturalism asks us to do] would be tantamount to stepping outside what we would recognize as integral, that is, undamaged human personhood" (p. 27). The self, as conceived by the naturalist, cannot function as a human subject. The naturalist's "superman of disengaged objectification" (Taylor, 1989, p. 27) then, is an unrealizable fiction.

The trouble is that the naturalist picture sees the self as an object, whereas the fact that "the self is crucially an object of significance to itself" (Taylor, 1989, p. 49) is a basic requirement of self-consciousness. Hence, the self cannot be defined in neutral terms (that is, outside a framework of questions about the good) as an object in causal relations to other objects. This implies that the self cannot be captured in an explicit description, as objects can. Nor can the self be considered apart from its meaning to itself (Taylor, 1989, pp. 33-34). Taylor's point here recalls Tillich's (1952) view that "you must participate in a self in order to know what it is" (p. 124). That the self is not an object suggests that the methods of natural science alone could not exhaustively account for the self. (Taylor, 1989, p. 34) Moreover, "the issue of identity is for us invariably a matter of strongly valued good" since "an identity is something that one ought to be true to, can fail to uphold, can surrender when one ought to" (Taylor, 1989, p. 30). Identity, then, is an essentially normative concept. Hence, the naturalist supposition that we can answer the question of who we are through reference to our contingent psychological states and preferences is "incoherent" (Taylor, 1989, p. 30). Thus, the naturalist postulate of a value-neutral stance is conceptually incoherent because it violates the BA principle.

Second, naturalists cannot help but cover up the explanatory deficits of their view by implicitly importing content from the first-person stance that their third-person, objective methodologies explicitly reject. Naturalist ontologies, which operate with a procedural model of reason, assume a value ontology that is more robust than the officially admitted view. Moreover, if Taylor is right and practical reasoning really cannot function without qualitative distinctions grounded in an encounter with being, naturalists cannot help but presuppose the qualitative distinctions they cannot explain (1989, p. 30). For instance, Taylor (1989) shows how the continued commitment to human rights of naturalist theorists presupposes a commitment to the constitutive good of intrinsic human dignity that gives the concept of rights its content (pp. 11-13). In this way, an implicit commitment to objective, intrinsic values continues to give content to theories and to empower practice, even when theories explicitly deny the existence of such values. Taylor (1989) concludes that "there is a great deal of motivated suppression of moral ontology among our contemporaries," a suppression that ultimately leads to a false self-understanding and to the "pragmatic self-contradiction" of presupposing in practice terms our theories deny (p. 10). Ultimately, the naturalist "lives within 
The Arbutus Review • 2018• Vol. 9, No. 1 • https://doi.org/10.18357/tar91201818381

a moral horizon which cannot be explicated by his own moral theory" (Taylor, 1989, pp. 31-32). The conceptual ineliminability of value distinctions ought to be more problematic for the naturalist. In fact, it reveals the conceptual priority of the first-person perspective from which values become intelligible to us. The theories that explicitly deny substantive reason thus implicitly affirm it by their failure to do without it in articulating their own alternative view.

Lastly, naturalism fails to supply an ontology that serves us both in our life uses and in theoretical explanation. If the practices by which we make sense of our lives presuppose qualitative distinctions and naturalism denies their possibility, it leaves a divide between theory and the kinds of everyday understandings by which we give shape and meaning to our experience.

Thus, naturalist ontologies of self and value fall afoul of the BA principle and lead to a false self-understanding that fails to explain the existential order of knowing by which we live our lives. If the naturalist should ask why he should accept the conclusion of this phenomenological analysis as decisive for ontology, Taylor (1989) answers that it is because "this is not only a phenomenological account but an exploration of the limits of the conceivable in human life, an account of its 'transcendental conditions"' (p. 32). Taylor makes disregarding the BA principle, and therefore the lessons of phenomenology, a logical fallacy.

\section{The Problematic Leap from Phenomenology to Ontology}

So far, Taylor has shown naturalist, procedural models of practical reason to be implausible accounts of self and value. He has used the Best Account principle as the basis for his argument for the superior explanatory power of his own model of substantive reason. However, Michiel Meijer (2014) has persuasively argued that while Taylor's transcendental arguments help him to ground values as structural requirements of well-functioning human subjectivity, "at the level of transcendental justification, Taylor is open to the charge that philosophical anthropology and moral phenomenology are just not the right methods to use in defense of ontological claims" (p. 452). Meijer argues that Taylor has failed to argue for the unity that underlies and justifies his "hybrid methodology." He goes on to suggest that Taylor's view evinces "an overly broad or relaxed notion of ontology (that) conceals the fundamental tension between the subjective and the objective" (p. 451). Meijer's objection is premised on a sharp ontological divide between the subjective and objective domains. From this premise, he goes on to argue that

Since transcendental arguments are anchored in human experience, it must also be clear that ontological questions lie beyond their scope. This implies that, in his critique of naturalism, Taylor himself cannot get away from the qualitative discontinuity between morality and ontology. (Meijer, 2014, p. 450)

I would argue that Meijer is correct in identifying this overreliance on transcendental arguments as the great weakness in Taylor's account. Moreover, I do not think that the gap in Taylor's argument can be filled even if we deny Meijer's premise that there is a divide between the subjective and the objective domains.

This is because Taylor's own account makes a distinction between the moment of creation and that of discovery within value judgments. This implies a distinction between the subjective (created) and objective (discovered) features of these judgments. On the one hand, creation takes the upper hand:

We find the sense of life through articulating it. And moderns have become acutely aware of how much sense being there for us depends on our own powers of articulation. Discovering here depends on, is interwoven with, inventing. (Taylor, 1989, p. 18) 
The Arbutus Review • 2018• Vol. 9, No. 1 • https://doi.org/10.18357/tar91201818381

On the other hand, constitutive goods are objective constraints that are there to be discovered. Thus, in moral space,

One orients oneself in a space which exists independently of one's success or failure in finding one's bearing, which, moreover, makes the task of finding these bearings inescapable. (Taylor, 1989, p. 30)

This distinction between the created and discovered features of judgments secures a mind-independent constraint on possible evaluation. For instance, if values were creations, we would have to say that child marriage is good or bad only in relation to a given individual's or culture's perspective. On this view, there is no perspective above culture or individual subjectivity that we could take in criticizing a given culture's ascription of positive value to such practices. A culture's say-so makes it so. And yet, this consequence deeply distorts a key feature of the phenomenology of value judgment, and namely the fact that the properties it discloses exist "independently of one's success or failure in finding one's bearing" (Taylor, 1989, p. 30) in relation to them. It is possible for us to fail to recognize the intrinsic worth of girls, just as it is possible to fail to constrain our behaviour according to this recognition by giving them the freedom to develop their potential before marriage.

As we have seen, it is in part their very mind-independence that makes constitutive goods meaningful. Part of their meaning stems from the fact that they provide stable points of reference that do not shift as our subjective assessments or social-pragmatic contexts invariably do. Instead, they anchor such assessments to real features that are meaningful because they are constraints on the self's possible movements. This could only make sense if we take seriously the claim that there is a "discovery" component to value judgment over and above any creativity it might involve. Nor can we explain these objective constraints in terms of the structure of practical reason alone, as a perspective-relativist reading of Murdoch's notion of value terms as "ideal limits" might suggest. This is because the applicability of these ideal limits in a given case presupposes our ability to discern the value properties of situations. Thus, the principle of respect for human dignity as an ideal limit in the child marriage case presupposes my ability to recognize a given child as having the property of dignity. The appropriate application of the principle presupposes the accurate recognition of the intrinsic properties of the situation.

But if Taylor's analysis presupposes the distinction between creation and discovery, and thus between the subjective and the objective moments of value judgment, then he owes us an account of what exactly bridges the gap between the two. Meijer is right to suggest that he fails to provide it. Below I explore a possible reconstruction of how the transcendental arguments of both Taylor and Murdoch can be supplemented with a metaphysical account, and hopefully show how the gap between phenomenology and ontology can be filled.

\section{The Phenomenology of Value as the Ontology of Self-Realization}

Donald Walhout's work The Good and the Realm of Values shows how the distinct methods of phenomenology, the ontology of self, and value theory converge on the Aristotelian notion of function, where function is defined as the activity in which the characteristic mode of being of a given thing finds its highest realization. For instance, the function of an eye is to see, and its good is its ability to realize this characteristic function without impediment (e.g., disease).

According to Walhout's perfectivist theory, value consists in the perfection of being that results from realizing one's characteristic function. Like Murdoch, he sees perfection, or completion of being, as a central regulative ideal of reason. He argues that this idea of completion is the most general concept of value from which all the other more specialized definitions proposed by the various theories of ethics implicitly derive their content. Thus, the utilitarian's analysis of value in 
terms of utility, the Kantian's in terms of good will, or the naturalist's in terms of psychological desire states, all implicitly presuppose the more logically primary notion of value as completion, fulfillment, or realization of being. As we shall see, by defining value in terms of function, which is arguably a core feature of all beings (since we individuate all things in terms of the functions they perform), Walhout successfully bridges the disparate domains of the first- and third-personal, the evaluative and the descriptive, being and value. In so doing, Walhout's constructive metaphysics fills the gap in Taylor's account between the subjective and the objective dimensions of value judgment, or between value as creation and value as discovery. I show in this section how the conceptual unity underlying Taylor's "hybrid methodology," as Meijer called it, can be revealed on the basis of such a constructive metaphysics. Ultimately, Walhout's discussion of value as functional realization makes explicit what the metaphysical underpinnings of the best account of our experience might look like.

I start with a description of Walhout's phenomenology, and I then trace more of its commonalities with Taylor's and Murdoch's accounts. Finally, I try to show how we can move from phenomenological descriptions to an analysis of the ontological commitments that these descriptions imply through the concept of functional realization. Walhout sees need as a unifying concept for value theory. In his view, any successful moral philosophy is built on an adequate account of the needs that drive us. He formulates the concept of ontological needs, which, in contradistinction with contingent, psychological needs and desires, belong to us by virtue of our nature, and thereby serve to guide us to the realization of this nature in a way that our contingent, often self-destructive desires do not. Ontological needs are reliable guides to the characteristic functioning of the self. The structure of these needs discloses facts about human nature and about its most fundamental relation to the rest of being. For example, the need for growth to a state that fully expresses a creature's characteristic form is an ontological need common to all living things. Similarly, as we saw in section 1, the need to unify experience into a coherent perspective or story might be classed as an ontological need. One might add that the need to express the image of the whole of which one is a part according to the constraints provided by one's starting point as a finite being is a fundamental ontological need. Walhout argues that two fundamental needs drive the self in all acts of valuation: the need for completion, which is born of our experience of our finitude and lack, and the need to exercise our capacity for spontaneous acts of creation, or what Walhout (1978) calls our need for "variety" (pp. 40-43).

The most basic ontological need of finite beings is the need for completion. Thus, the first ground of evaluation is our experience of insufficiency, lack, and need. According to Walhout, the phenomenology of value shows experience to be a striving for completion that springs from our awareness of our finitude and of the precariousness that characterizes any finite, contingent condition. This experience generates in us a desire for completion that acts as a structuring principle of consciousness. One could say that this striving for completion is exhibited by the structure of intentionality itself, as a perpetual tending-to, and as a restless striving to attain an object that only provisionally brings the mental act to completion, only to have that provisional unity unravelled again as consciousness moves on in search of another encounter with another object. Any moment of experience is an unstable resting point for consciousness. The present moment is never experienced as a sufficiency unto itself. In William Barrett's (1979) poignant phrase, "since consciousness points beyond itself, it is in its very being a self-transcendence" (p. 132). All intentionality is in this way a self-transcending activity that is intrinsically aimed at completion. Values are, on Walhout's view, the response of the whole subject to the whole of being according to the subject's innermost need for completion.

The experience of the chasm that lies between the incomplete, fragmentary beings that we are and the realized beings that we recognize that we ought to be is, according to Walhout, the mainspring of morality and of value experience generally. This experience of incompleteness reveals 
The Arbutus Review • 2018• Vol. 9, No. 1 • https://doi.org/10.18357/tar91201818381

an ontological divide between, on the one hand, the actual, psychological self, and on the other, what Walhout calls the "essential" self, which is the pattern of the properly functioning self and the source of ontological needs. On Murdoch's analysis, we could say that the former is a given in experience, while the latter remains a regulative ideal of reason by which we evaluate our experience. Thus, our experience in its most basic moments is characterized by the nagging sense that "Here I am; Yonder is my real self" (Walhout, 1978, p. 62). Our goal in action is so to relate to being as to bridge the gap between the two selves. If Walhout is right, then the motivating source of value judgment is the recognition of what I would call the "Two Self" distinction between the empirical subject and the essential self that directs practical reason to its realization. Recall that for Taylor, I determine who I am by measuring the distance between my actual, imperfect, and fragmentary experience against a constitutive good that I implicitly recognize as defining an ideal of completeness that is greater than the one that I have attained (see section 1). I can only measure the imperfection that I am by referring to an object that exhibits greater completeness than I do. For Taylor, as for Walhout, since I can only define my actual self in reference to the essential self that pulls me to its realization, I know that my actual, empirical self is less real to me than is the ideal held up by my essential, yet-to-be-realized self. The regulative ideal of completion without which I cannot reason about my condition infinitely recedes from me the closer that I progress toward it.

The need for completion exhibited by a self-transcending finitude shows one reason why we value things. We value things because it is only by finding the right way of relating ourselves to them that we are delivered to our own possible completion as beings (Walhout, 1978, p. 43). Value judgments point us to those aspects of being that fill the existential deficiency experienced by the self, thereby completing and fulfilling our being. Using Walhout's terminology, we could say that intentionality relates us to being as a perficiens. Walhout (1978) calls a perficiens "any entity which contributes to the fulfillment or perfection of another entity" (p. 16). As such, a perficiens is the objective support of valuational activity. I would argue that Walhout's perficiens is the metaphysical correlate of Taylor's constitutive good. I judge constitutive goods to be fit objects of love and allegiance by which I can direct my actions, my strivings, and my becomings, so that I may more fully be, because they exhibit a completeness that I lack.

While the need for completion is grounded in our being insofar as it is subject to necessity, the second basic ground of evaluation, the need for creative action, stems from our being insofar as it is free. This second "need" involves us more fully as active agents and as creators of the shape of our lives.

Notice that the concept of function played a central role in structuring the phenomenological account. What moves us in experience is the striving for completion, and completeness is defined as the ability of a given entity to act according to its characteristic function. However, the notion of function is not only central to the first-personal, phenomenological account. It is also central to the ontological account of the objective constraints of value judgments that make sense of our claims that we discover, rather than merely create, values. Value judgments are grounded in being if "they pick out structure and function in the world. Structure and function are what exhibit perfection of being" (Walhout, 1978, p. 206). Moreover, "function relates the world more immediately to purposive worth, which often seems random and inexplicable" (Walhout, 1978, p. 210). Function, then, describes not merely the formal features of a thing and is not restricted to characterizing its causal role in a larger system defined by external causal relations. Rather, it is the ontic ground of our judgments of value by virtue of its intrinsic purposiveness. In this account, value is a property of our intentional relations as subjects to objective functional features in the world. Walhout's analysis of value in terms of function helps account for the mind-independent goods that Taylor was concerned to cover with his notion of strong evaluation. This is because values, as fulfillments of function, cannot exist solely as mental states. Fulfillments are objective. This implies that I can 
believe that I am fulfilled, and yet be wrong in my assessment of my condition. Consider addiction. The addict's struggle can be seen as an emblem of the universal conflict between the two selves that power value judgment. My desires, as an addict, lead me to pursue precisely those things that destroy me. What is good for me, then, cannot depend merely on my contingent desires and interests. Moreover, as an addict, I can believe that I am fulfilled in getting what I want, and yet fail to be accurate in evaluating my situation. This possibility refutes subjectivism, or any identification of value with subjective states. It also refutes standard naturalist attempts to reduce value to the subject's contingent projects, desires, or goals.

Thus, the most comprehensive objective ground of value judgments is objective fulfillment, not conscious liking. Value judgments have both a descriptive and a normative character. The descriptive side of value judgments reveals the parameters of objective fulfillment, and whether or not they are met in a given situation. Moreover, we can generate norms on the basis of these descriptions (Walhout, 1978, p. 57). Thus, as we saw above in our analysis of the function of the eye, describing the function of things implicitly involves us in qualitative distinctions that help us to specify the course of their ideal functional development. This explains the normative judgments we ordinarily make when we distinguish between "good" and "bad" functioning. I can know, for instance, that my desires as an addict are functioning badly as reliable guides to value. If this is so, we can find out whether a conscious liking is good or bad by seeing whether it is an ingredient in a situation in which one of our ontological needs is in fact fulfilled. Hence, value judgments have both a descriptive and a prescriptive character. Moreover, the latter presupposes the former, since function is the object of conscious enjoyment (Walhout, 1978, p. 207). As such, there can be no subjective enjoyments without objective fulfillments of function. Contrary to much modern moral philosophy, Walhout shows that experience is, logically, a secondary category to being.

Our paradigm has difficulty conceptualizing values as fulfillments because it operates with a thing-centric ontology that has difficulty recognizing relational properties. Values, as fulfillments, are properties not of things, but of situations. "Value judgments describe or define relational situations in which some objective condition, being, or reality fulfills some existential human need or is the completing object of some variety capacity" (Walhout, 1978, p. 56). For instance, interlocutors in a conversation act as one another's perficiens, since each shapes the other in discourse. The conversation, then, is the fulfillment of the individuals' function as self-shaping beings by taking them up into a larger pattern. As a relational situation of mutual perfecting of all parties involved, a conversation is the paradigmatic example of a value situation. Walhout's (1978) insistence that "the good is alwaya [...] relational" precludes individualism (p. 167). Individuals cannot attain functional realization as atoms in a void. Rather, they must relate themselves appropriately to those objects in reality that support their process of self-realization. Thus, to complete itself, the individual must occupy the place appropriate to its kind in the greater scheme of things that provides it with the fuel for growth that allows its nature to unfold (Walhout, 1978, p. 207). If values are properties of relational situations rather than merely of mental states, then it is no surprise that strong evaluations can pick out non-human goods, as Taylor insisted that they must.

Moreover, it is not only humans that have a being that can be perfected. Rather, the value of perfectibility applies to all finite beings. Thus, human values must be subsumed under a more generalizable conception of the good as completion of being. Because of this, we have no reason to assume, as much modern value theory does, that the good is a property that applies only to human conscious states. And because the concept of value generalizes across all beings by being tied to function, value is not some peripheral issue in ontology. Rather, it is an integral component of our best concept of the real. This value theory can form the basis for a truly ecological ethics, as well as for an ecological concept of self.

The purpose of this short section has been to provide an introductory sketch of the analysis of 
The Arbutus Review • 2018• Vol. 9, No. 1 • https://doi.org/10.18357/tar91201818381

value in terms of function. For a fuller treatment of this many-faceted topic, as well as for replies to some of the main objections facing the theory, I refer readers to Walhout's book-length treatment. This cursory discussion has, hopefully, shown that the goal of an ontology of value is to identify the objective conditions of fulfillment for any being (Walhout, 1978, p. 42). The ultimate value is the state of complete actuality (which corresponds to the traditional concept of absolute being). Since no finite being can enjoy such a state, for us, value lies in the reciprocal relation of mutual-fulfillment whereby we find as great a completion as our finite natures allow. Values lie also in the acts that relate us appropriately to the rest of being: "the response of the whole self to the whole of reality is relevant to every detail and [...] ultimate fulfillment requires such a response" (Walhout, 1978, p. 234). Walhout proposes "harmonious perfecting" as the foundational concept of value that comprehends all others. Just as the best theory is the one that unifies the most of what we know, so the best act is the one that aims at the good of being conceived as a whole, since it is only through such acts that we can experience an intensification of being that transcends the limitations of the finite self (Walhout, 1978, p. 68). Value theory thus starts with phenomenology, but culminates in metaphysics because it concerns the best things. Our incomplete experience tells us that the best thing for us is not the given, empirical subject we are. Rather, it is the subject placed in that relation to the whole that alone can complete it as the individual that it is.

\section{Conclusion}

Walhout's analysis of value in terms of function shows a way to fill in the gaps that remain between phenomenology and ontology in Taylor's critique of third-personal naturalism. Walhout shows that function is a concept that bridges between the first- and third-person stances, between the subjective and the objective, between the being of selves, as functional units, and value. What this paper attempts to show is that Taylor needs more than just transcendental arguments and phenomenological redescription if he is to surmount the incoherence of the currently reigning naturalist account of "frameworkless" selves. That "more" is a systematic metaphysics that can bridge the gap between first- and third-person perspectives by giving an account of the intentional relation in which value originates.

Ultimately, I argue that Walhout (1978) is right to remind us that the central problem of philosophy is determining the nature of the relation between goodness and being (p. 170). Ethics, together with any other normative endeavour such as epistemology, presupposes an affirmative answer to this metaphysical question, and, if Taylor is right, so does our best phenomenological account of the self. Third-personal naturalism cannot ground the affirmation of being as good, according to both Taylor and Walhout. But, perhaps a first-personal naturalism might. This is a naturalism that takes seriously Taylor's Best Account principle that states that phenomenology, and in particular moral phenomenology, can and must place constraints on ontology. The first-person stance has both a logical and an ontological priority in any account of self for the reasons given above. Moreover, we need a better account of reason that takes seriously the analysis of value concepts as ideal limits that Murdoch, Taylor, and Walhout provide.

However the argument for a revised naturalism may turn out in the end, I believe that the discussion above shows that the self is first and foremost a moral agent, not an object of scientific description. This simple observation challenges the heart of the currently reigning ontology of self. 


\section{References}

Barrett, W. (1979). The illusion of technique: A search for meaning in a technological civilization. Garden City, NY: Anchor Press/Doubleday.

Meijer, M. (2014). Strong evaluation and weak ontology. The predicament of Charles Taylor. International Journal of Philosophy and Theology, 75(5),440-459.10.1080/21692327.2015.1019913

Murdoch, I. (1986). The sovereignty of good. New York, NY: Ark Paperbacks.

Taylor, C. (1989). Sources of the self. Cambridge, MA: Harvard University Press.

Tillich, P. (1952). The courage to be. Binghampton, NY: Yale University Press.

Walhout, D. (1978). The good and the realm of values. London, England: University of Notre Dame Press. 